\title{
Política, Burocracia e Mídia: Lutas simbólicas em torno da divulgação das audiências públicas na Câmara dos Deputados
}

\author{
Politics, Bureaucracy and Media: Symbolic Fights about public hearings \\ disclosure of public hearings in the Brazilian House of Representatives
}

\author{
La política, la burocracia y los medias: Luchas simbólicas alrededor de la \\ divulgación de las audiencias públicas en la Cámara de Representantes del Brasil
}

\author{
Antonio Teixeira de Barros ${ }^{1}$ \\ Adriana Resende Monteiro ${ }^{2}$ \\ Miguel Gerônimo da Nóbrega Netto ${ }^{3}$
}

\begin{abstract}
Resumo: O texto analisa, com base na perspectiva teórica de Pierre Bourdieu, as lutas simbólicas em torno da definição e da reformulação da política de divulgação jornalística das audiências públicas realizadas pela Câmara dos Deputados. Para compreender como se operam essas lutas simbólicas, o estudo teve como base entrevistas em profundidade com todos os servidores que exerceram o cargo de coordenador de Jornalismo da Secretaria de Comunicação da Câmara, no período de 2001 a 2015. Também foram entrevistados os secretários-executivos das 23 comissões permanentes, a fim de fazer o contraponto entre os dois campos: o jornalístico e o político. As conclusões iniciais chamam atenção para a existência de um processo multifatorial de lutas simbólicas, em várias etapas, envolvendo redefinições e negociações constantes entre os gestores da informação e os representantes das comissões que promovem as audiências públicas, incluindo os próprios parlamentares e o corpo funcional das comissões envolvido nos debates.
\end{abstract}

Palavras-chave: Jornalismo político. Divulgação legislativa. Audiências públicas. Valores profissionais. Valores políticos.

Abstract: This paper analyzes the symbolic fights over the definition and redesign of public hearings disclosure policy conducted by the House of Representatives, based on the theoretical perspective of Pierre Bourdieu. To understand how they operate these symbolic fights, the study was based on interviews in depth with all civil servants that have exercised the office of Journalism Coordinator of the House Communications Office, from 2000 to 2014 were also interviewed the executive secretaries of the 23 standing committees in order to make the contrast between the two camps: the informational and political. Initial findings draw attention to the existence of a multifactorial process of symbolic fights in several stages involving redefinitions and constant negotiations between managers of information and representatives of committees that promote public hearings, including parliamentarians themselves and functional body of committees involved in the discussions.

Keywords: Fights symbolic. legislative disclosure. public hearings. professional values. political values.

\footnotetext{
${ }^{1}$ Doutor em Sociologia pela UnB. Docente e pesquisador do Programa de Pós-Graduação do Centro de Formação da Câmara dos deputados (Cefor). E-mail: antonibarros@gmail.com

2 Mestra em Ciência Política pela UnB. Pesquisador do Programa de Pós-Graduação do Centro de Formação da Câmara dos deputados (Cefor). E-mail: driresende@yahoo.com

3 Mestre em Poder Legislativo. Docente e pesquisador do Programa de Pós-Graduação do Centro de Formação da Câmara dos deputados (Cefor). E-mail: miguel.netto@ camara.leg.br
} 
Resumen: El artículo analiza las luchas simbólicas sobre la definición y el rediseño de la política de divulgación de las audiencias públicas realizadas por la Cámara de Representantes, basado en la perspectiva teórica de Pierre Bourdieu. Para entender cómo funcionan estas luchas simbólicas, el estudio se basó en entrevistas en profundidad con todos los servidores que hayan ejercido el cargo de Coordinador de Periodismo de la Oficina de la Casa de Comunicaciones, 2000-2014. También se entrevistó a los secretarios ejecutivos de las 23 comisiones permanentes con el fin de hacer que el contraste entre los dos campos: el informativo y político. Los resultados iniciales señalan la existencia de un proceso multifactorial de las luchas simbólicas en varias etapas que implican redefiniciones y negociaciones constantes entre los gestores de la información y los representantes de los comités que promueven las audiencias públicas, incluyendo los propios parlamentarios y el cuerpo funcional de comités que participan en las discusiones.

Palabras-clave: Periodismo. Divulgación legislativa. Audiencias públicas. Valores profesionales. Valores políticos.

\section{Introdução}

O texto analisa as lutas simbólicas em torno da definição e da reformulação da política de divulgação das audiências públicas realizadas pela Câmara dos Deputados, com base na perspectiva teórica de Bourdieu (1989; 2011a; 2011b). Para o autor, os sistemas simbólicos, enquanto instrumentos estruturados e estruturantes de comunicação e conhecimento, cumprem sua função política de imposição e de legitimação da dominação de um grupo sobre os demais. O campo de produção simbólica é, portanto, um microcosmo das lutas simbólicas. Em outras palavras, os sistemas simbólicos produzidos por um corpo de especialistas entram em disputa pela legitimação perante um corpo burocrático ou político, por exemplo, como no caso das disputas em torno da divulgação das audiências públicas realizadas pela Câmara dos Deputados, por meio de seu sistema de mídias institucionais, como a Rádio Câmara, a TV Câmara e a Agência Câmara de Notícias.

Para compreender como se operam essas lutas simbólicas, o estudo teve como base entrevistas em profundidade com todos os titulares do cargo de coordenador de Jornalismo da Secretaria de Comunicação da Câmara, desde que passou a existir a função de articulação e coordenação da cobertura, antes mesmo da criação formal da Coordenação de Jornalismo (CJor) ${ }^{4}$. Também foram entrevistados os secretáriosexecutivos de 23 comissões permanentes, a fim de fazer o contraponto entre os dois campos: o informacional e o político. O período estudado vai de 2000 a 2014.

A CJor surgiu com a atribuição de articular os critérios editoriais de cobertura

\footnotetext{
${ }^{4}$ A criação formal da CJor se deu no ano de 2003. Porém, a função de articulação e coordenação da cobertura já existia antes mesmo da institucionalização do órgão. 
legislativa, incluindo as audiências públicas. Desde então, seis servidores efetivos atuaram como titulares da CJor, todos jornalistas do quadro efetivo da instituição. As entrevistas foram realizadas no primeiro semestre de 2015, em uma perspectiva qualitativa, pautada pelo princípio sociológico de pesquisa compreensivista, mais especificamente apoiado no pressuposto metodológico de Giddens (1984) de que existe um processo de dupla hermenêutica nesse tipo de pesquisa. Isso significa que o conhecimento sociopolítico deve passar primeiro pela análise da percepção dos próprios agentes envolvidos, no caso, os entrevistados. Em segunda instância é que passa pelo olhar dos pesquisadores. Esse foi o princípio metodológico que orientou a pesquisa.

\section{Política, burocracia e jornalismo}

Os estudos sobre burocracia e política geralmente ressaltam as dicotomias entre os dois campos, apontando para a racionalidade da primeira e a irracionalidade da segunda (WEBER, 1999; BOURDIEU, 1996; KLÜGER, 2015). Por irracionalidade entende-se uma lógica própria da política, movida pela paixão e os afetos, ao contrário da lógica burocrática, cuja virtude estaria na impessoalidade, o que exclui os sentimentos e as emoções. A política envolve necessariamente a disputa de interesses de poder (WEBER, 1999), com suas lutas e dissensões (BOURDIEU, 2011). A burocracia, por sua vez, é associada a comportamentos regulados por normas e procedimentos que "conseguem fazer de suas opções políticas decisões de natureza técnica" (KLÜGER, 2015, p.91). Afinal,

O feito de que a desvalorização do político em contraposição ao técnico seja convergente com o senso comum é um trunfo poderoso de neutralização da ação política dos técnicos. A crença na racionalidade da ciência, da técnica e das formas de gestão modernas acabaria por proteger as escolhas apresentadas como técnicas da crítica, impedindo que os fundamentos da ciência e da técnica e as finalidades que movem a ação dos técnicos fossem julgadas em suas dimensões políticas, ou seja, em sua irracionalidade (KLÜGER, 2015, p. 91).

Bourdieu é um dos autores que mais acentuam o caráter político da burocracia, caracterizada por ele como estruturas de dominação cuja legitimidade advém da competência técnica ancorada no capital simbólico dos títulos, diplomas e dos concursos para o recrutamento pelo Estado (BOURDIEU, 2011). Como estrutura de dominação, na visão de Bourdieu, o campo burocrático é uma instância de lutas políticas, embora seu caráter político seja ocultado por "um conjunto bem-sucedido de atos mágicos" capazes de mascarar os inúmeros fundamentos não racionais e arbitrários da escolha dos "homens competentes", identificados como técnicos. Trata-se de um mecanismo da própria 
burocracia para legitimar sua posição de dominação e autoapresentar-se como "um grupo social específico, o mais preparado para exercer o poder de modo racional e neutro" (KLÜGER, 2015, p.92).

Trata-se do que Bourdieu (2011a) denomina de ilusão tecnocrática, que resulta da atribuição de uma racionalidade técnica aos especialistas, o que contribui "para apagar as marcas sociais de suas tomadas de posição":

\begin{abstract}
Informadas pelas visões de mundo vigentes nos espaços em que foram socializados, na família, na escola, na vida mundana, as tomadas de decisão estão vinculadas, necessariamente, à posição por eles ocupada no espaço social, não sendo, portanto, universais. A apresentação das decisões dos técnicos como racionais, neutras, técnicas e eficazes, ou seja, a conversão de suas crenças e de sua visão de mundo em princípios universais, seria assim, um mecanismo de reforço e legitimação da dominação, quer dizer, de reprodução da distribuição desigual de recursos, inclusive do próprio poder (KLÜGER, 2015, p.92).
\end{abstract}

Em ambientes burocráticos, o emprego do termo político "ora designa aqueles que não possuem competências especializadas ora denomina aqueles que possuem a qualificação técnica, mas que são acusados de ser francamente influenciados por ideais políticos" (KLÜGER, 2015, p.79), passando a falsa ideia de neutralidade do campo da tecnocracia, como um lugar neutro, cujos atores adotam um lugar de fala ancorado no domínio da técnica (BOURDIEU e BOLTANSKI, 2008; PINTO, 2009; PINZANI, 2013). Interessa aos atores desses espaços a negação do caráter ideológico dos saberes por eles produzidos e suas respectivas representações do mundo (CHIARAMONTE, 2012, p. 92). A burocracia se apresenta como um grupo universal, "um órgão de reflexão e um instrumento racional encarregado de realizar o interesse geral" (BOURDIEU, 2011a, p.95). Os atos burocráticos pertencem à categoria dos atos oficias, ou seja, "realizados em situação de autoridade, por pessoas autorizadas" (p. 112).

Para Bourdieu (2011a), as burocracias instituem programas de ação política "que pretendem impor uma visão particular do Estado, de acordo com os interesses e os valores associados à posição ocupada por aqueles que os produzem" (BOURDIEU, 2011, p.96). Esses programas de ação constituem formas de dominação simbólica inerente ao campo de poder estatal, uma vez que o Estado "é o lugar por excelência da concentração e do exercício do poder simbólico" (p.108). Para o autor, a burocracia é ainda uma forma de exercício do poder criado do Estado, ou seja, o poder de criar aparatos, instituições e espíritos, sob o regime de submissão dóxica à ordem estabelecida. O Estado detém o poder de produzir e impor "as categorias de pensamento que utilizamos espontaneamente a todas as coisas do mundo, e ao próprio Estado" (p.91). Nesse sentido, as burocracias 
instituem programas de ação política "que pretendem impor uma visão particular do Estado, de acordo com os interesses e os valores associados à posição ocupada por aqueles que os produzem" (BOURDIEU, 2011a, p.96).

O capital simbólico dos lugares neutros e da burocracia é a credibilidade técnica ou expertocracia (PINZANI, 2013). Por essa razão, os parlamentares costumam convidar especialistas para os debates legislativos por eles protagonizados. Aqui cabem algumas observações acerca dessa estratégia dos parlamentares de utilizarem argumentos de especialistas para legitimar o debate político nas audiências públicas, como parte do regime de opinião caracterizado por racionalidade e discussão, o que confere o princípio de autoridade, com papel especial para os especialistas neste sentido (HABERMAS, 1994).

Cumpre ressaltar que os especialistas são convidados pelos deputados, o que já indica que o conhecimento perito ou especializado (expert knowledge) pode ser utilizado para constituir discursos fortes ${ }^{5}$, a fim de inspirar confiança pública no trabalho das comissões que promovem os debates. Afinal, os agentes do discurso especializado são portadores de um poder simbólico, cujo capital é a credibilidade técnica, respaldada pelas lógicas adversárias (Kant De Lima, 2010) ${ }^{6}$. O debate político, por sua vez, segundo a visão do autor citado, é pautado pela lógica do contraditório, cuja característica principal é a polarização entre teses. Isso difere do conhecimento científico, baseado na premissa de que é a autoridade do argumento e não o argumento de autoridade que define o destino das disputas. Como veremos adiante, os parlamentares recorrem à autoridade do argumento dos especialistas para reforçarem o argumento de autoridade deles próprios, como forma de controlar os debates políticos.

Por outro lado, Pinzani (2013, p.160) argumenta que, respaldado no discurso da tecnocracia ou na expertocracia,

\footnotetext{
O homem político que toma suas decisões com base no saber especializado dos experts não é responsável pessoalmente por elas, pois são a consequência lógica da aplicação prática de tal saber. Isso significa, em primeiro lugar, a despersonalização da política. O político se torna um simples técnico que reage a fatores externos ao adotar as medidas necessárias. Seu espaço de manobra é extremamente reduzido e seu lugar pode ser tomado, a qualquer momento e sem nenhum problema, por outro técnico - sob condição de que este disponha do mesmo saber que aquele.
}

\footnotetext{
${ }^{5}$ No sentido usado por Goffman (1974) e Bourdieu (1998), ou seja, um discurso a serviço da ordem dominante, a fim de legitimar e manter situações sociais, políticas ou econômicas.

${ }^{6}$ Trata-se das lógicas típicas do debate acadêmico, pautado pelo debate racional e divergente. São as lógicas de produção de verdades fundadas "em consensos provisórios sobre fatos que se constroem pela reflexão e a explicitação das diferentes perspectivas dos envolvidos, em processo de argumentação demonstrativa, que visa ao convencimento de todas as partes legítimas envolvidas" (Kant de Lima, 2010, p.29).
} 
Long (2004) destaca a relevância do conhecimento produzido a partir das diferentes formas de mediação e interfaces socioculturais ${ }^{7}$. Nesse processo, o próprio debate em si é um instrumento de produção e depuração de conhecimentos, o que é potencializado e amplificado pela partilha de experiências e de perspectivas, sejam elas convergentes ou divergentes. Aliás, para o autor, os contextos discursivos com ideias divergentes são mais produtivos para o amadurecimento de concepções controversas, além de alimentar e retroalimentar o conhecimento dos atores que participam dos debates proporcionados pelas arenas argumentativas que funcionam sob a lógica de interfaces sociais e políticas. Nesse processo, o autor ressalta o papel dos experts individualmente, dos atores políticos, dos partidos, dos parlamentos e demais instituições políticas, científicas, sociais e culturais. Essas interfaces são permeadas por diferentes relações e dispositivos de poder ${ }^{8}$. Tais interfaces também são relevantes para interconectar as arenas de conhecimento técnico especializado, de debate político e a esfera do conhecimento comum $^{9}$, ou seja, aquelas formas de saberes diretamente relacionados com os distintos campos experienciais do mundo vivido.

Outra questão relevante no debate sobre a relação entre política e burocracia é o papel das emoções e dos afetos. Nesse sentido, Castro $\left(2009\right.$, p.485) ${ }^{10}$ destaca que a ação política não é necessariamente baseada no cálculo racional. Aliás, para o autor, as formas políticas geralmente são mobilizadas por paixões e afetos. Mouffe (2005) também sublinha o papel das emoções nas trocas políticas. Em sua avaliação, a política não só é feita de mero cálculo racional de interesses, mas também de elementos simbólicos e subjetivos, como os afetos. Para a autora, os afetos são uma das mais poderosas forças que movem os sujeitos no campo da política.

Os afetos parecem também mover as dinâmicas jornalísticas na divulgação das audiências públicas da Câmara dos Deputados, conforme será analisado adiante. A respeito da força simbólica dos afetos na mídia, Ribeiro (2005) argumenta que, tanto quanto a política, o jornalismo é um mediador de afetos, ao mesmo tempo em que também é movido por afetos, apesar dos clichês de objetividade e imparcialidade. Esses elementos

\footnotetext{
7 Abordagem similar é adotada por Pires e Vaz (2014), com aplicação na análise das interfaces socioestatais de participação social nos processos políticos.

${ }^{8}$ Para uma análise específica sobre as interfaces socioestatais e suas implicações políticas, consultar Pires e Vaz (2014).

${ }^{9}$ O conhecimento comum também é reconhecido por Maffesoli (2010) como um campo fundamental para a construção da trama societal, a partir do compartilhamento intersubjetivo da experiência comum dos sujeitos sociais, o que deve ser considerado com um dispositivo de relativização do conhecimento técnico especializado e dos saberes políticos. Essa trama põe em relevo a pluralidade dos aspectos da vida social, com a pluralidade de perspectivas e riquezas de controvérsias e abordagens.

${ }^{10}$ A citação é baseada em Ion e Ravon (1998).
} 
seriam utilizados para conquistar a credibilidade da audiência, embora a relação dos veículos de comunicação com seus públicos seja imbuída de elementos da esfera da subjetividade, como a confiança e a preferência. Trata-se de uma forma de dominação simbólica, como ressalta Bourdieu (1989; 2011b).

Seguindo os argumentos de Bourdieu, ao contrário da burocracia que se legitima pela aparência de impessoalidade, o campo político e o campo jornalístico ${ }^{11}$ apresentam em comum a personalização. O político, apesar de fazer parte de um partido e de um campo mais amplo, é eleito e reconhecido de forma personalizada e ele próprio busca o capital da reputação pessoal, o que será necessário para manter seu mandato e para conquistar novos pleitos eleitorais. O jornalista, da mesma forma, busca o capital da reputação para si, embora seja integrante de uma equipe de mídia, de uma instituição midiática, como um jornal ou uma emissora de TV. Como são regidos por regras próprias, produzidas e legitimadas de forma endógena, os campos político e jornalístico se distinguem exatamente por essas regras internas. Ambos são entendidos por Bourdieu (2011b, p.195) como "universos nos quais operam critérios de avaliação que the são próprios e que não teriam validade em outro campo".

Para o autor, as condições sociais do funcionamento do campo político funcionam “como um lugar em que certo número de pessoas, que preenchem as condições de acesso, joga um jogo particular do qual os outros estão excluídos” (2011b, p.197). Isso significa que o campo político "repousa sobre uma exclusão, um desapossamento". Afinal, "quanto mais o campo político se constitui, mais ele se autonomiza". Assim, o fato de o campo político ser autônomo e ter sua lógica própria, "lógica que está no princípio dos posicionamentos daqueles que nele estão envolvidos, implica que existe um interesse político específico, não automaticamente redutível aos interesses dos outorgantes do mandato". Para o autor, "há interesses que se definem na relação com as pessoas do mesmo partido ou contra as pessoas dos outros partidos". O funcionamento do campo produz uma espécie de fechamento:

Esse efeito observável é o resultado de um processo: quanto mais um espaço político se autonomiza, mais avança segundo sua lógica própria, mais tende a funcionar em conformidade com os interesses inerentes ao campo, mais cresce a separação com relação aos profanos (BOURDIEU, 2011b, P.199).

Um dos fatores dessa evolução no sentido de alcançar uma autonomia crescente

\footnotetext{
${ }^{11}$ Usamos o conceito de campo, definido por Bourdieu (2011b, p. 201) um campo de forças, e um campo de lutas para transformar as relações de forças. "Em um campo como o campo político ou o campo religioso, ou qualquer outro campo, as condutas dos agentes são determinadas por sua posição na estrutura da relação de forças característica desse campo no momento considerado".
} 
e, portanto, de uma separação crescente em relação aos demais campos, "é o fato de que o campo político é o lugar de produção e operação de uma competência específica, de um sentido do jogo próprio de cada campo" (p.199). O campo político pode ser descrito “como um jogo no qual o que está em disputa é a imposição legítima dos princípios de visão e divisão do mundo social (p.206). Existem, portanto, no campo político, "lutas simbólicas nas quais os adversários dispõem de armas desiguais, de capitais desiguais, de poderes simbólicos desiguais" (p.204).

Segundo Bourdieu (2005), o campo jornalístico também funciona com base em regras próprias e apresenta relativa autonomia em relação aos demais campos sociais. Autonomia relativa porque ao mesmo tempo ele é regido por suas próprias regras e protocolos técnicos e profissionais. O campo jornalístico é um campo social poroso, permeável aos demais campos, como a economia e a política. O jornalista reporta-se diariamente ao que acontece na vida social, ou seja, o discurso jornalístico não é sobre si mesmo, como no caso do campo político, mas sobre economia, política, turismo, religião, artes etc. As normas próprias e os protocolos técnicos funcionam como mecanismos para conferir credibilidade ao jornalismo, visto que seu poder está em fazer crer. Seu principal capital simbólico, portanto, é a credibilidade e a confiança das audiências, conforme Bourdieu.

Fazendo um paralelo entre campo político e campo jornalístico, podemos afirmar que ambos são ancorados no poder simbólico, ou seja, uma forma soft de poder que se estabelece pelo poder de palavra, pelas imagens e discursos, constituindo e fazendo impor uma visão de mundo, uma forma de pensar e de se posicionar perante os fatos. Trata-se de um poder que depende da adesão ou cumplicidade dos dominados, ou seja, dos eleitores (no caso do campo político) e dos leitores, ouvintes ou telespectadores (no caso do campo jornalístico). Por se tratar de relações de comunicação, os discursos político e jornalístico disputam formas de imposição de uma visão legítima do mundo social.

Conforme ressalta Bourdieu (2005, p.36), “essa imposição consiste na definição dos princípios dominantes de visão e de divisão da realidade social”. Em outras palavras: políticos e jornalistas disputam o poder simbólico de nomeação e classificação do mundo social, ou, seja, o estabelecimento dos critérios de legitimidade da ação social. Essa disputa, segundo Bourdieu, provoca interferências do campo jornalístico no campo político, uma vez que o primeiro constrói representações simbólicas sobre o segundo. Ademais, o jornalismo atinge grandes audiências, ao contrário dos políticos. Além das 
reportagens cotidianas sobre política, Bourdieu cita como exemplo os jornalistas especializados em comentar e analisar a política. Assim, para descrever o campo político atualmente, "é preciso incluir essas categorias de agentes, pela simples razão de que eles produzem efeitos no campo político" (BOURDIEU, 2011b, p.201).

Por essa razão é que Bourdieu ressalta algumas assimetrias entre o campo político e o campo jornalístico quando se trata da produção e do controle da visibilidade política. Mesmo que os políticos, como no caso dos parlamentares, disponham cada vez mais de recursos e dispositivos próprios de divulgação, como websites, mídias sociais e assessorias de imprensa, os meios de comunicação convencionais ainda detêm maior poder quando se trata de espaço de exibição e de julgamento da política, seja pelo noticiário, pelos editoriais e pela opinião de comentaristas dos próprios veículos. Além disso, as mídias operam a partir de dispositivos que lhes favorecem, chamados por Bourdieu de estruturas invisíveis, que resultam numa espécie de censura invisível ou num modo de ocultar mostrando. Exemplos desses dispositivos são a seleção dos temas a serem noticiados e comentados, a escolha das imagens mais impactantes, o uso de gravações de áudio, a escolha das fontes jornalísticas que serão convidadas e "autorizadas" a se manifestar sobre os temas políticos, o tempo de fala, o recorte da fala mediante a edição, entre outros procedimentos.

No caso em estudo há uma particularidade a ser considerada, pois trata-se de um sistema de comunicação institucional, mantido pela própria Câmara dos Deputados, o que se enquadra na categoria de mídias das fontes, isto é, veículos mantidos pelas próprias instituições públicas (Sant'Anna, 2009) ou mídias táticas, ou seja, meios alternativos aos veículos comerciais, capazes de produzir agendamentos e enquadramentos diferenciados, conforme o interesse dos emissores (JURIS, 2005), a exemplo dos veículos de comunicação da Câmara. Esses sistemas de mídia ainda não apresentam uma identidade definida, ora sendo analisados como veículos de comunicação institucional, ora como comunicação pública, ora como serviços de propaganda e de relações públicas, como discutem Barros e Bernardes (2015), que preferem a denominação de sistemas híbridos de comunicação, uma vez que combinam técnicas e estratégias de várias áreas da comunicação, como jornalismo, publicidade, propaganda e relações públicas, mesmo quando são rotulados de jornalismo, como é o caso em exame neste artigo. Ao analisarem o caso da Câmara dos Deputados, os autores afirmam que: 
Sob a perspectiva institucional, as mídias legislativas são veículos governamentais ou estatais, isto é, controlados por instâncias de governo e com objetivos declaradamente políticos. Entretanto, os produtores têm algumas restrições ao conceito, exatamente porque, como jornalistas, não querem que sua atividade seja identificada como comunicação política, ainda que admitam a existência desse fator no seu trabalho (BARROS; BERNARDES, 2015, p.30).

Os autores ressaltam ainda que "no caso das mídias legislativas, a autoridade jornalística dos profissionais é constantemente desafiada pelos demais atores sociais que participam da instituição" (p.32). Entre esses atores estão os próprios deputados e o staff das comissões que promovem as audiências públicas. Por essa razão, esses atores políticos e burocráticos "tentam continuamente interferir no processo de definição de regras de noticiabilidade e modificar os procedimentos jornalísticos” (p.32). Nas palavras dos autores, há uma disputa constante dos jornalistas da instituição, não apenas com os parlamentares "que exercem o papel duplo de "patrão" e "fonte de informação", mas também com os próprios colegas de outros setores da Câmara para definição do que merece e do que não merece ser divulgado sobre a instituição, a exemplo das audiências públicas.

Segundo os autores supracitados, essas disputas resultam em tensões permanentes entre as esferas política, burocrática e os gestores da informação jornalística, com seus interesses divergentes e suas visões particulares sobre o papel dos veículos de comunicação. Se para os jornalistas a função das mídias da Câmara é de informar o cidadão sobre o que acontece na arena legislativa, mesmo quando se trata de algo negativo para a imagem da instituição, para os parlamentares e o staff das comissões, a principal função é percebida como instrumental, ou seja, selecionar os fatos sempre sob uma perspectiva positiva e favorável à reputação dos parlamentares e das instituições. Essas divergências também aparecem quando se trata das audiências públicas, conforme será demonstrado posteriormente.

\section{AUDIÊNCIAS PÚBLICAS}

Oriunda do direito anglo-saxão, a audiência pública é um dos mecanismos para assegurar a participação da sociedade civil nos debates políticos e administrativos. No Brasil, é resultado das motivações democratizantes que inspiraram a Constituição de 1988 (BARROS; BERNARDES, 2010). O Regimento Interno da Assembleia Constituinte previa formas de apresentação de sugestões de entidades representativas da sociedade por meio de plebiscito, referendo e apresentação de emendas populares. Entretanto, essas 
formas que fortaleceram o caráter democratizante da nova Carta eram extremamente complexas de efetivar e, por isso, alcançaram pouco resultado (GUERRA, 2010). As audiências públicas, portanto, tornaram-se o instrumento mais recorrente para a participação popular na elaboração das políticas públicas, tanto na esfera do Poder Legislativo como nos demais poderes. No caso específico do Poder Legislativo, esse instrumento é um dos mais expressivos no que se refere à função política do Parlamento como órgão mediador entre o Estado e a sociedade civil, conforme destacam Weber (1999) e Habermas (1997). Essa mediação, segundo Troiano (2015) também pode funcionar como mecanismo de negociação de interesses, como um espaço institucional para filtrar acessos de atores e organizações ao parlamento, além de institucionalizar relações entre os atores envolvidos.

É oportuno ressaltar que se trata de um mecanismo inserido no rol dos direitos de participação política. Assim, o instituto das audiências públicas baseia-se no pressuposto de que o cidadão não deve ser mero observador da cena pública ou agente passivo do processo político ou administrativo. Trata-se, pois, de um expediente considerado indispensável para o fortalecimento das práticas de democracia e de cidadania no contexto atual. Diferentemente da sessão pública, na qual o público apenas assiste ao debate, na audiência pública os representantes da coletividade podem se manifestar de forma ativa, assegurando aos cidadãos o direito de colaborar e de ser ouvido. Dessa forma, esse instrumento permite o fortalecimento dos vínculos entre a sociedade e o Estado, além de possibilitar a renovação do diálogo entre os agentes públicos e a população. É também considerado "mecanismo idôneo de formação de consenso da opinião pública", além de “elemento de democratização do poder e modo de participação no poder público" (DAL BOSCO, 2002, p. 155).

O Poder Legislativo tem nas audiências públicas espaços democráticos de debates entre parlamentares e a sociedade que subsidiam os parlamentares para o exercício de suas funções institucionais (GUERRA, 2010). A realização dessas audiências decorre de comando constitucional (art. 58, parágrafo $2^{\circ}$, inciso II, da CF de 1988), cabendo às duas Casas do Congresso Nacional sua implementação. Segundo Celso Ribeiro Bastos (1995) "as audiências públicas com entidades da sociedade civil são realizadas quando questões de interesse social ou mesmo de segmentos específicos da sociedade forem suscitadas, tais audiências, portanto, configuram espaços voltados ao debate coletivo".

A Câmara dos Deputados incorporou às rotinas de trabalho o debate com entes da sociedade civil. Esses debates são previstos pelo Regimento Interno da Câmara dos 
Deputados (RICD, artigos 255-258). O primeiro deles define as linhas gerais que as comissões devem seguir para a execução dos debates:

Art. 255. Cada Comissão poderá realizar reunião de audiência pública com entidade da sociedade civil para instruir matéria legislativa em trâmite, bem como para tratar de assuntos de interesse público relevante, atinentes à sua área de atuação, mediante proposta de qualquer membro ou a pedido de entidade interessada.

Na sequência, o RICD define a dinâmica da seleção dos convidados:

\begin{abstract}
Art. 256. Aprovada a reunião de audiência pública, a Comissão selecionará, para serem ouvidas, as autoridades, as pessoas interessadas e os especialistas ligados às entidades participantes, cabendo ao Presidente da Comissão expedir os convites.

$\S 1^{\circ}$. Na hipótese de haver defensores e opositores relativamente à matéria objeto de exame, a Comissão procederá de forma que possibilite a audiência das diversas correntes de opinião.

$\S 2^{\circ}$. O convidado deverá limitar-se ao tema ou questão em debate e disporá, para tanto, de vinte minutos, prorrogáveis a juízo da Comissão, não podendo ser aparteado.
\end{abstract}

Parágrafo único. Será admitido, a qualquer tempo, o traslado de peças ou fornecimento de cópias aos interessados".

Percebe-se que as principais características das audiências públicas defendidas pelo RICD são a transparência e o debate efetivo sobre matéria relevante e de interesse coletivo, com espaço para todas as correntes de opinião encontráveis na sociedade. Tratase de uma concepção idealizada de comissão como um corpo político orgânico e funcionalmente cooperativo e integrado. A esse respeito, é oportuna a menção à noção de Bourdieu de comissão como "um conjunto de pessoas investidas de uma missão de interesse geral e conclamadas a transcender seus interesses particulares para produzir propostas universais" (BOURDIEU, 2011, p.123)

A primeira audiência pública realizada pela Câmara dos Deputados após a promulgação da Carta Constitucional de 1988 ocorreu em 03/11/1988, promovida pela Comissão Interpartidária do Salário Mínimo, com a presença de representantes patronais e sindicais, conforme relata em discurso publicado pelo Diário do Congresso Nacional o então deputado Maurílio Ferreira Lima (BRASIL, 1998, p. 3784). Desde o ano de 2000, a Agência Câmara passou a divulgar informações sobre as audiências públicas, o que aumentou de imediato o volume de requerimentos apresentados, conforme revela em entrevista $^{12}$ um dos ocupantes do cargo de coordenador de Jornalismo da Secretaria de

\footnotetext{
${ }^{12}$ As entrevistas foram realizadas sob regime de anonimato, a fim de evitar constrangimentos aos entrevistados, visto 
Comunicação da Câmara:

A divulgação nas mídias da Casa provocou um rápido crescimento desses debates, o que mostra um nítido efeito da visibilidade parlamentar. Antes da divulgação, o número de audiências por ano era inexpressivo. No ano de 2000, por exemplo, foram realizadas cerca de dez audiências. Em 2002, foram 32. Em 2012 passou para 320. Isso mostra que, com o espaço midiático institucional, o volume aumentou de forma visível. O que observamos é que o interesse dos parlamentares não era tanto em debate propriamente dito, mas na visibilidade garantida pela divulgação.

A cada ano, as 23 comissões permanentes e as várias comissões especiais da Câmara realizam anualmente quase mil audiências públicas ${ }^{13}$. A maioria absoluta delas ocorre de terça a quinta-feira, período em que os parlamentares concentram sua atividade em Brasília. Num cálculo simples, percebe-se que a média de eventos de terça a quinta é de quase 15 por dia. Em raras ocasiões os deputados realizam audiências nos estados, geralmente para tratar de temas de interesse das comissões especiais. Por esse motivo, muitos eventos acabam acontecendo ao mesmo tempo, nos plenários das comissões (BERNARDES e BARROS, 2010).

O Quadro 1 apresenta um levantamento das audiências públicas realizadas no período de 2001 a $2015^{14}$. A oscilação entre os anos pares e ímpares se explica pela interferência dos anos eleitorais na redução da atividade parlamentar de modo geral, o que também afeta as audiências públicas. A tendência, contudo, tem sido de crescimento. Se em 2001 foram 492 audiências, em 2015 foram 931.

\section{Quadro 1 - Audiências públicas por ano}

\begin{tabular}{|r|c|c|c|}
\hline & ANO & N & $\%$ \\
\hline 1 & 2001 & 492 & 6,94 \\
\hline 2 & 2002 & 193 & 2,72 \\
\hline 3 & 2003 & 562 & 7,93 \\
\hline 4 & 2004 & 378 & 5,33 \\
\hline 5 & 2005 & 418 & 5,90 \\
\hline 6 & 2006 & 185 & 2,61 \\
\hline 7 & 2007 & 602 & 8,49 \\
\hline 8 & 2008 & 445 & 6,28 \\
\hline 9 & 2009 & 626 & 8,83 \\
\hline
\end{tabular}

envolver julgamentos e críticas de ordem subjetiva.

${ }^{13}$ Além das audiências, a Câmara realiza quase 500 eventos por ano, entre seminários, conferências, congressos e exposições, conforme Bernardes e Barros (2010).

${ }^{14}$ Apesar de a divulgação ter iniciado em 2000, não há registro documental dos dados deste ano nos arquivos do Departamento de Comissões. 


\begin{tabular}{|c|c|c|c|}
10 & 2010 & 260 & 3,67 \\
\hline 11 & 2011 & 487 & 6,87 \\
\hline 12 & 2012 & 387 & 5,46 \\
\hline 13 & 2013 & 772 & 10,89 \\
\hline 14 & 2014 & 349 & 4,92 \\
\hline 15 & 2015 & 931 & 13,14 \\
\hline & TOTAL & $\mathbf{7 0 8 7}$ & $\mathbf{1 0 0}$ \\
\hline
\end{tabular}

Fonte: Elaboração própria, com dados do Departamento de Comissões da Câmara dos Deputados.

O Quadro 2 apresenta um levantamento conforme as comissões realizam as audiências públicas. No período estudado houve predomínio das audiências públicas promovidas pelas Comissões parlamentares de inquérito $(11,37 \%)$ e pelas chamadas comissões especiais $(11,26 \%)$. No caso das comissões permanentes, a distribuição é relativamente similar, com percentuais pouco expressivos de diferença, exceto no caso das Comissões de Cultura; de Desenvolvimento Urbano; de Viação e Transportes. Cabe salientar que nem todas essas comissões funcionam desde o ano de 2000. Algumas foram sendo criadas ao longo do tempo, a exemplo da Comissão de Cultura, que antes fazia parte da Comissão de Educação e conquistou autonomia em 2013.

Cabe salientar que apresentamos o levantamento completo aqui apenas como ilustração, com a ressalva de que o foco do artigo são as comissões permanentes que já funcionavam desde a implantação da política de divulgação das audiências públicas ${ }^{15}$. A justificativa para essa escolha é que se trata de conjunto de comissões que atuam de forma permanente e continuada, ou seja, elas constituem a essência da estrutura da Câmara dos Deputados, com um trabalho que faz parte do cotidiano burocrático e político. As demais são distintas, criadas para fins específicos e com uma duração determinada. São tão diversas que para estudá-las seriam necessárias outras estratégias metodológicas, principalmente o estudo de caso.

\footnotetext{
${ }^{15}$ Por essa razão, foram excluídas do estudo as comissões criadas em 2015, as quais ainda estavam se estruturando durante o período da pesquisa e ainda não havia um background no que se refere à relação com os gestores da divulgação institucional. São as seguintes: Comissão de Defesa dos Direitos da Mulher, Comissão de Defesa dos Direitos da Pessoa Idosa e a Comissão de Defesa dos Direitos das Pessoas com Deficiência.
} 


\section{Quadro 2 - Audiências por comissões (2001-2015)}

\begin{tabular}{|c|c|c|c|}
\hline & COMISSÃO & $\mathbf{N}$ & $\%$ \\
\hline 1 & Comissões parlamentares de inquérito & 806 & 11,37 \\
\hline 2 & Comissões especiais & 798 & 11,26 \\
\hline 3 & Comissão de Seguridade Social e Família - CSSF & 481 & 6,79 \\
\hline 4 & $\begin{array}{l}\text { Comissão de Agricultura, Pecuária, Abastecimento e Desenvolvimento Rural - } \\
\text { CAPADR }\end{array}$ & 373 & 5,26 \\
\hline 5 & Comissão de Educação - CE & 341 & 4,81 \\
\hline 6 & $\begin{array}{l}\text { Comissão de Integração Nacional, Desenvolvimento Regional e da Amazônia - } \\
\text { CINDRA }\end{array}$ & 334 & 4,71 \\
\hline 7 & Comissão de Trabalho, de Administração e Serviço Público - CTASP & 332 & 4,68 \\
\hline 8 & Comissão de Direitos Humanos e Minorias - CDHM & 319 & 4,50 \\
\hline 9 & Comissão de Defesa do Consumidor - CDC & 306 & 4,32 \\
\hline 10 & Comissão de Relações Exteriores e de Defesa Nacional - CREDN & 301 & 4,25 \\
\hline 11 & Comissão de Meio Ambiente e Desenvolvimento Sustentável - CMADS & 288 & 4,06 \\
\hline & Comissão de Fiscalização Financeira e Controle - CFFC & 283 & 3,99 \\
\hline 12 & $\begin{array}{l}\text { Comissão de Desenvolvimento Econômico, Indústria, Comércio e Serviços- } \\
\text { CDEICS }\end{array}$ & 276 & 3,89 \\
\hline 13 & Comissão de Ciência e Tecnologia, Comunicação e Informática - CCTCI & 258 & 3,64 \\
\hline 14 & Comissão de Finanças e Tributação - CFT & 224 & 3,16 \\
\hline & Comissão de Minas e Energia - CME & 185 & 2,61 \\
\hline 15 & Comissão de Turismo - CTUR & 175 & 2,47 \\
\hline 16 & Comissão de Desenvolvimento Urbano - CDU & 174 & 2,46 \\
\hline 17 & Comissão de Segurança Pública e Combate ao Crime Organizado - CSPCCO & 159 & 2,24 \\
\hline 18 & Comissões criadas em 2015-2016 & 158 & 2,23 \\
\hline 19 & Comissão de Viação e Transportes - CVT & 148 & 2,09 \\
\hline 20 & Comissão de Legislação Participativa - CLP & 134 & 1,89 \\
\hline 21 & Comissão de Constituição e Justiça e de Cidadania - CCJC & 84 & 1,19 \\
\hline 22 & Comissão de Cultura - CCULT & 52 & 0,73 \\
\hline 23 & Comissão do Esporte - CESPO & 48 & 0,68 \\
\hline 24 & Comissões externas & 44 & 0,62 \\
\hline \multirow[t]{2}{*}{25} & Comissão Mista de Orçamento & 6 & 0,08 \\
\hline & TOTAL & 7.087 & 100 \\
\hline
\end{tabular}

Fonte: Elaboração própria, com dados do Departamento de Comissões da Câmara dos Deputados. 


\section{ANÁliSe DAS ENTREVISTAS - A VISÃO DOS DIVULGADORES INSTITUCIONAIS}

As entrevistas chamam atenção para a existência de um processo multifatorial de lutas simbólicas, em várias etapas, envolvendo redefinições e negociações constantes entre os gestores da informação da CJor e os representantes das comissões que promovem as audiências públicas, incluindo os próprios parlamentares, os secretários-executivos e corpo funcional dos colegiados. A partir do exame minucioso das entrevistas foram identificadas cinco fases de lutas simbólicas, as quais serão detalhadas a partir de agora. A primeira - e a mais pacífica - consistiu na ampliação da visibilidade e na adequação dos conteúdos aos padrões jornalísticos, com o início da cobertura (2000-2002). Essa fase inicial é resumida por um dos informantes da seguinte forma:

\footnotetext{
Como se trata de uma novidade tanto para nós da Secom como para os deputados e os servidores das comissões, houve uma certa euforia interna, um clima de colaboração, com um espírito de que estávamos fazendo algo útil para a Câmara dos Deputados, para os parlamentares e para a sociedade. Além disso, a iniciativa foi bem recebida pelas comissões, pois havia um diagnóstico de que a imprensa não se interessava pelo trabalho das comissões. A iniciativa da Secom foi vista como capaz de tentar suprir essa lacuna de informação.
}

Nesse período, conforme os relatos dos informantes, as comissões preparavam material prévio sobre cada uma das audiências públicas realizadas para os jornalistas da Câmara dos Deputados, a fim de contribuir ao máximo para a divulgação dos debates. "E como estávamos no início do projeto, sem nenhuma experiência prévia para nos balizar, a gente publicava praticamente tudo, sem grandes alterações no conteúdo e no formato", descreve o mesmo informante. Entretanto, com o passar do tempo e o aumento do número das audiências públicas, "tivemos que ser mais seletivos, pois não dava mais para cobrir todas as audiências e fazer longas matérias, praticamente um relatório ou uma ata da reunião. A partir daí, então, iniciaram os conflitos, explica o entrevistado.

Inicia-se, então, a segunda fase (2003-2005), na qual os conflitos se acentuaram, quando a CJor passou a estabelecer critérios editoriais específicos para pauta e enquadramento, o que desagradou os parlamentares e as equipes das comissões. Desde que a Agência Câmara passou a divulgar informações sobre as audiências públicas, aumentou de imediato o volume de requerimentos apresentados, conforme revela em entrevista ${ }^{16}$ um dos ocupantes do cargo de coordenador de Jornalismo da Secretaria de

\footnotetext{
${ }^{16}$ As entrevistas foram realizadas sob regime de anonimato, a fim de evitar constrangimentos aos entrevistados, visto envolver julgamentos e críticas de ordem subjetiva.
} 


\section{Comunicação da Câmara:}

A divulgação nas mídias da Casa provocou um rápido crescimento desses debates, o que mostra um nítido efeito da visibilidade parlamentar. Antes da divulgação, o número de audiências por ano era inexpressivo. No ano de 2000, por exemplo, foram realizadas cerca de dez audiências. Em 2001, foram 492. Tudo isso por causa do efeito da visibilidade nas mídias da Casa. Isso mostra que o interesse dos parlamentares não era tanto em debate propriamente dito, mas na visibilidade garantida pela divulgação.

Conforme os relatos, "foi uma fase de conflitos diários, com reclamações de todas as comissões, de todos os parlamentares envolvidos nos debates". Por outro lado, enquanto aumentava a demanda pela divulgação, o corpo de jornalistas para fazer a cobertura se manteve o mesmo. "Para cobrir esses eventos, contávamos na época com equipe de aproximadamente dez jornalistas, o que tornava inviável divulgar todas as audiências". Diante dessa impossibilidade, "nós deixamos de ser vistos como aliados das comissões e dos parlamentares no trabalho de divulgação e passamos a ocupar o ingrato papel de 'boicotadores' do trabalho dos deputados, conforme o discurso do pessoal das comissões". As disputas simbólicas foram intensificadas com a discussão sobre os critérios próprios de cada veículo da Secom (jornal, rádio, TV e internet). Conforme comenta um dos informantes da pesquisa:

Cada veículo tem sua linguagem própria, suas características e limitações. O jornal impresso tem o limite de páginas, o rádio usa notas curtas, a TV prioriza eventos com imagens expressivas e assim por diante. Entretanto, os deputados queriam que cada veículo fizesse a cobertura do jeito deles, ou seja, cada parlamentar exigia o maior tempo e o maior espaço possível para a audiência pública que ele requereu ou presidiu ou no debate no qual ele usou o microfone. Não se contentavam com uma notinha ou um registro breve, dentro das possibilidades de cada veículo.

Um exemplo emblemático dessa fase está no seguinte relato de um dos entrevistados:

A situação ficou tão difícil que alguns deputados proibiram a entrada dos jornalistas da Secom nas audiências públicas, ou seja, reagiram de uma forma tão extremada que recusaram a divulgação. Aliás, não só recusaram, como também proibiram que fizéssemos nosso trabalho. Na prática eles estavam nos dizendo: 'se não for para nos atender e fazer do nosso jeito, não queremos que a divulgação seja realizada'. Foi necessária a intermediação do Presidente da Casa para acalmar os ânimos e explicar aos deputados que a realidade era outra, com um alto volume de audiências e uma pequena equipe para cobrir os trabalhos. 
A quarta fase (2006-2010), resultante da ampliação da visibilidade, incluiu novos atores no campo de lutas simbólicas, como as entidades e os grupos de pressão e de interesse envolvidos na agenda das audiências. "A situação ficou ainda mais conflituosa, pois além das queixas diárias dos parlamentares e dos funcionários das comissões, passamos a receber um volume expressivo de e-mails e telefonemas dos representantes das entidades e grupos de interesse que participam das audiências públicas", relata outro informante. Percebemos nessa quarta a fase a intensificação dos conflitos em função da entrada em cena de novos atores nas lutas simbólicas em torno da divulgação dos debates. A participação desses atores da sociedade civil por um lado é positiva, pois mostra que o debate adquiriu maior visibilidade social, mas também chama atenção para as disputas por visibilidade entre os parlamentares e esses atores. Trata-se do que Miguel (2002) denomina de estratégias de controle da visibilidade política, ou seja, cada ator envolvido nos debates tenta interferir na divulgação, de modo a impor a sua visão sobre o tema discutido.

Para os entrevistados, essa fase constitui "um complicador para o trabalho de divulgação, pois além da deficiência de jornalistas para a cobertura, tínhamos que dedicar muito para atender os telefonemas e responder os e-mails dessas entidades". Por se tratar de uma disputa pelo enquadramento da informação, "essas pessoas em geral são muito assertivas, insistentes e capazes de ir às últimas instâncias, como reclamar diretamente com a hierarquia superior, como o Secretário de Comunicação da Câmara ou até mesmo o Presidente da Casa, em algumas situações". Por ter sido rotineiro, nessa fase, os relatos mostram que "isso gerava um clima de desconfiança interna, como se nós estivéssemos boicotando as visões e opiniões dos representantes dessas entidades, como se estivéssemos trabalhando contra a sociedade civil".

A quinta fase (2010-2014) amplificou ainda mais esse cenário, com o debate sobre convergência midiática e o início das transmissões das audiências pela internet. "Ao iniciarmos um novo sistema, logicamente que problemas também apareceram, de ambos os lados, ou seja, dos parlamentares e da sociedade civil", relata outro informante. As disputas simbólicas nesse caso giram em torno do capital de reputação da TV Câmara e do sistema WebCâmara: 
Cabe lembrar que estamos falando de uma época em que a TV Câmara já estava consolidada como um veículo reconhecido no meio político, com mais de dez anos de uma trajetória que já tinha feito da TV o veículo mais relevante para a divulgação da atividade parlamentar, na visão dos próprios deputados. Temos pesquisas internas que mostravam isso. E de repente surge uma nova janela para a divulgação das audiências públicas, ou seja, a internet, que ainda não contava com a popularidade de hoje em dia. Para nós da Secom, oferecer às comissões mais uma alternativa era algo muito positivo, mas a ideia foi recebida com ressalvas, tanto pelos parlamentares como as entidades da sociedade civil, explica um dos informantes.

Os conflitos surgiram não só em decorrência da novidade da transmissão ao vivo das audiências públicas pela internet na época, mas também por uma questão de hierarquia. As audiências consideradas "mais importantes" pela Secom eram transmitidas pela TV, enquanto aquelas de menor relevância é que eram transmitidas pela internet. Segundo os relatos, a dificuldade, de ambos os lados, era o entendimento de que um tema poderia despertar a atenção de um maior número de pessoas, enquanto outros, apesar de importantes, "dialogam com públicos menores":

Para nós da Secom era claro que uma audiência pública sobre um tema como o combate à violência contra a mulher, por exemplo, tinha muito mais público do que uma discussão sobre a plantação de açaí nativo. Em um caso como esse, para nós, não havia dúvida de qual seria transmitido pela TV e qual seria divulgado pela internet. O problema é que tanto o deputado que estava presidindo a discussão sobre o açaí como os ambientalistas presentes na reunião não concordaram com a nossa perspectiva, mas aos poucos isso foi mudando, com a ampliação do uso da internet e o reconhecimento hoje de que pode ser um veículo até mais relevante do que a TV.

\section{Análise do questionário - a visão das comissões}

Com o intuito de avaliar como as equipes das comissões permanentes da Câmara percebem a divulgação realizada sobre as audiências públicas, foi realizada uma pesquisa censitária, com os secretários-executivos das 22 comissões permanentes da Câmara em $2015^{17}$. Apesar de todo o avanço na política de divulgação apontado pelos entrevistados da Secom, $50 \%$ dos secretários-executivos das comissões avaliam a divulgação como regular, 45,45\% acham boa e 4,55\% acham ruim, como se vê no Quadro 3.

\footnotetext{
17 Atualmente são 25 comissões permanentes, mas para a aplicação do questionário excluímos aquelas que foram criadas em 2015, por não haver ainda experiência acumulada. Trata-se das Comissões de defesa dos direitos da Pessoa com deficiência (CPD); da Mulher (CMULHER); e do Idoso (CIDOSO).
} 
Quadro 3 - Como você avalia a divulgação das audiências públicas pelos veículos de comunicação da Câmara?

\begin{tabular}{|l|r|r|}
\hline RESPOSTAS & $\mathbf{N}$ & $\boldsymbol{\%}$ \\
\hline Regular & 11 & 50,00 \\
\hline Boa & 10 & 45,45 \\
\hline Ruim & 1 & 4,55 \\
\hline Ótima & 0 & 0 \\
\hline TOTAL & $\mathbf{2 2}$ & $\mathbf{1 0 0}$ \\
\hline
\end{tabular}

Fonte: Elaboração própria.

No campo para comentários sobre essa questão, os respondentes reconhecem que a divulgação "às vezes é prejudicada pela grande quantidade de eventos realizados ao mesmo tempo, o que impossibilita a transmissão de todas as audiências”. Outros reclamam que "em alguns casos, a divulgação ocorre com considerável atraso, o que pode ocorrer alguns dias após a realização do evento". Outro respondente fez o seguinte registro:

A divulgação de audiências públicas melhorou muito. Houve tempo em que a divulgação somente ocorria se fosse feita solicitação formal à Secom, mesmo assim nem sempre conseguíamos a transmissão ao vivo ou a divulgação posterior de um resumo dos debates. Hoje eu vejo o quanto evoluiu, principalmente por causa da internet.

A respeito da carência de pessoal para maior divulgação, outro respondente escreveu:

Tenho conhecimento da carência de servidores na Casa, além disso não se pode olvidar que o número de comissões permanentes e temporárias é significativo, porém não é aceitável que alguns eventos de relevante interesse nacional não sejam divulgados de maneira apropriada.

Comparando com o passado, $50 \%$ observam pouca diferença em relação à divulgação realizada atualmente, enquanto 45,45\% consideram que há muita diferença, como mostra o Quadro 4. 
Quadro 4 - Você observa diferenças em relação à divulgação feita no passado e o trabalho realizado atualmente?

\begin{tabular}{|l|r|r|}
\hline RESPOSTAS & $\mathbf{N}$ & $\mathbf{\%}$ \\
\hline Pouca diferença & 11 & 50,00 \\
\hline Muita diferença & 10 & 45,45 \\
\hline Até certo ponto & 1 & 4,55 \\
\hline Nenhuma diferença & 0 & 0,00 \\
\hline TOTAL & $\mathbf{2 2}$ & $\mathbf{1 0 0}$ \\
\hline
\end{tabular}

Fonte: Elaboração própria.

No que se refere às reclamações dos parlamentares, os dados mostram uma tendência de pacificação das lutas simbólicas em torno da definição dos critérios para a divulgação das audiências públicas. A metade dos respondentes (50\%) respondeu que os deputados reclamam eventualmente; 40,91\% responderam que não há reclamação e 9,09\% acham que as reclamações acontecem atualmente com frequência mediana (Quadro 5).

Quadro 5 - Os deputados que requerem as audiências públicas reclamam da forma como elas são divulgadas?

\begin{tabular}{|l|r|r|}
\hline RESPOSTAS & $\mathbf{N}$ & $\mathbf{\%}$ \\
\hline Reclamam eventualmente & 11 & 50 \\
\hline Não reclamam & 9 & 40,91 \\
\hline Reclamam com frequência média & 2 & 9,09 \\
\hline Reclamam com muita frequência & 0 & 0 \\
\hline TOTAL & $\mathbf{2 2}$ & $\mathbf{1 0 0}$ \\
\hline
\end{tabular}

Fonte: Elaboração própria.

Segundo o relato por escrito de um dos informantes, "os deputados que requerem as audiências públicas reclamam principalmente do espaço midiático destinado ao evento, pois eles sempre acham que um tema superimportante acaba sendo divulgado sem destaque ou de forma muito resumida e superficial". Outros secretários-executivos apontaram reclamações de parlamentares quanto à falta de cobertura fotográfica. "Muitas vezes só há o registro textual, sem nenhuma foto do parlamentar que requereu a reunião". Ao concordar com as críticas dos deputados, outro informante assim escreveu: "as críticas 
dos parlamentares geralmente demonstram insatisfação com o não reconhecimento da importância da matéria debatida".

Perguntados sobre quais seriam as reclamações e críticas mais recorrentes dos deputados, obtivemos as seguintes respostas:

- A principal crítica não é da cobertura, mas da ausência dela, quando isso ocorre.

- Eventualmente, há críticas sobre conteúdos, considerados insuficientes ou por não abranger aspectos de interesse de deputados.

- Pedem que o evento apareça no Jornal da Câmara ou que a TV Câmara mostre flashes do que acontece nas comissões. É importante para a Casa que o trabalho das comissões, pouco conhecido pela população de modo geral e onde tanta coisa positiva acontece, seja melhor divulgado.

- Reclamam que nem sempre o ponto de vista do deputado é que vai ser destaque na divulgação. Algumas vezes predominam exatamente as críticas ao ponto de vista do parlamentar.

- Há situações em que a opinião dos representantes do povo, eleitos pelo voto popular, recebe menos importância nas matérias, que priorizam os movimentos sociais de esquerda, como se eles fossem os representantes da sociedade.

- A divulgação se concentra nos temas de maior repercussão nacional, principalmente quando os temas discutidos estão na pauta da grande mídia. A ideia que temos é que a agenda dos parlamentares que não se enquadra nos "grandes temas" não interessa nem mesmo para os veículos da Casa.

Como podemos observar, o repertório de críticas e queixas é variado, mas aponta para uma direção comum: que a divulgação contemple as reivindicações de uma disseminação focada na perspectiva e enfoque dos próprios parlamentares. Isso mostra uma visão de audiência pública como um instrumento para promover a visibilidade dos parlamentares, de suas opiniões de forma personalista. Mesmo os depoimentos que se referem aos interesses da população e da sociedade, na realidade são centrados numa cultura de que o parlamentar deve ser o centro da divulgação realizada pelas mídias da Câmara, embora as audiências públicas sejam consideradas instrumentos de participação para dar voz aos representantes da sociedade civil.

A tendência dos secretários-executivos das comissões é concordar com as reclamações dos parlamentares em relação à divulgação das audiências públicas. O que varia é o tipo de concordância, como se vê no Quadro 6. Os dados mostram que 40,91\% concordam totalmente, enquanto $27,27 \%$ concordam na maioria dos casos e em alguns casos, respectivamente. Apenas um respondente (4,55\%) não concorda. 
Quadro 6 - Você concorda com as reclamações e críticas dos deputados?

\begin{tabular}{|l|r|r|}
\hline RESPOSTAS & $\mathbf{N}$ & \% \\
\hline Concordo totalmente & 9 & 40,91 \\
\hline Concordo na maioria dos casos & 6 & 27,27 \\
\hline Concordo em alguns poucos casos & 6 & 27,27 \\
\hline Não concordo & 1 & 4,55 \\
\hline TOTAL & $\mathbf{2 2}$ & $\mathbf{1 0 0}$ \\
\hline
\end{tabular}

Fonte: Elaboração própria.

Em relação ao conjunto das equipes das comissões, 36,36\% dos servidores não reclamam da divulgação das audiências públicas, enquanto 31,82\% reclamam eventualmente, $27,27 \%$ reclamam com frequência média e apenas um respondeu que os servidores reclamam com muita frequência (Quadro 7).

\section{Quadro 7 - Há críticas e reclamações sobre a divulgação por parte da equipe de servidores e colaboradores das comissões?}

\begin{tabular}{|c|c|c|}
\hline RESPOSTAS & $\mathrm{N}$ & $\%$ \\
\hline Os servidores não reclamam & 8 & 36,36 \\
\hline Os servidores reclamam eventualmente & 7 & 31,82 \\
\hline Os servidores reclamam com frequência média & 6 & 27,27 \\
\hline Os servidores reclamam com muita frequência & 1 & 4,55 \\
\hline TOTAL & $\mathbf{2 2}$ & $\mathbf{1 0 0}$ \\
\hline
\end{tabular}

Fonte: Elaboração própria.

Perguntados se haveria aspectos a serem aprimorados na divulgação das audiências públicas (pergunta aberta), obtivemos as seguintes respostas:

\footnotetext{
- A divulgação deve ser feita para atingir o público interessado no assunto da audiência pública, não somente internamente, já que a audiência pública é uma oportunidade da Câmara estar em contato com as demandas da sociedade. Quando os próprios deputados se encarregam da divulgação dos seus eventos, o público alvo é atingido, e a audiência conta com grande participação popular.

- Acredito que as audiências públicas mais relevantes deveriam vir em destaque na primeira página do site da Câmara. Um banner que ficasse atualizando de tempos em tempos. Acho o caminho a ser percorrido no site pelo público em geral muito longo para ter acesso à divulgação de eventos importantes.
}

Quanto à avaliação dos veículos de comunicação da Câmara no que se refere à divulgação das audiências públicas, 32,26\% dos respondentes consideram que a Agência 
Câmara é que melhor cumpre essa função. A Rádio Câmara aparece em segundo lugar, com $29,03 \%$, enquanto $25,81 \%$ responderam que não percebem diferença e consideram os veículos igualmente eficientes. O Jornal da Câmara e a TV Câmara contam com o mesmo percentual de preferência dos informantes, ou seja, 6,45\% (Quadro 8).

Esses dados mostram que as disputas dos parlamentares para que as audiências públicas fossem divulgadas preferencialmente pela TV Câmara já não são mais relevantes na atualidade. Se a TV era considerada o veículo de maior reputação em termos de divulgação da atividade parlamentar, perdeu essa popularidade para a internet atualmente, com a primazia da Agência Câmara (na internet). Embora as respostas não tenham sido dadas diretamente pelos parlamentares, pode-se deduzir isso, uma vez que os secretáriosexecutivos das comissões lidam diretamente com os parlamentares no cotidiano e ouvem as opiniões dos deputados. Quanto ao papel da internet atualmente, um dos respondentes escreveu o seguinte relato:

Um serviço que ajudou muito na divulgação do trabalho das comissões foi a transmissão ao vivo pela internet de todos os eventos, já que a TV Câmara não dispõe de recursos técnicos para cobrir na íntegra todas as reuniões das comissões. Isso foi um ganho muito positivo para a sociedade que nos procura para saber se o evento de seu interesse será transmitido ao vivo pela web.

Especificamente sobre a Agência Câmara, destacamos o seguinte comentário de um dos informantes da pesquisa:

A Agência Câmara é o melhor veículo para a divulgação das audiências públicas por dois aspectos. Primeiro, ela divulga com antecedência $o$ acontecimento do evento. Segundo, ela cobre a exposição dos convidados fazendo um breve resumo da fala de cada expositor, ressaltando todas as colocações relevantes do tema em discussão. Para o público em geral é possível se ter uma ideia do que foi abordado apenas pela leitura das notícias da Agência Câmara.

Um dos secretários-executivos chamou atenção para a baixa atuação dos parlamentares nos debates promovidos pelas comissões na forma de audiências públicas:

Na verdade, não vejo que o problema esteja na divulgação ou nos veículos. Todos eles fazem seu trabalho, mas não vejo grande alcance na divulgação de tais audiências. O problema é que aqueles que deveriam ser os maiores interessados, os parlamentares, raramente compõem um quadro qualificado, pouquíssimos comparecem às audiências e, quando comparecem, é só para fazer a foto ou um breve pronunciamento diante das câmeras e dos microfones. 
Quadro 8 - Qual veículo você acha que cumpre melhor a função de divulgar as audiências públicas?

\begin{tabular}{|l|r|r|}
\hline RESPOSTAS & $\mathbf{N}$ & $\mathbf{\%}$ \\
\hline A Agência Câmara é a mais eficiente. & 10 & 32,26 \\
\hline A Rádio Câmara é a mais eficiente & 9 & 29,03 \\
\hline Não percebo diferenças entre os veículos e considero todos igualmente eficientes & 8 & 25,81 \\
\hline O Jornal da Câmara é o mais eficiente & 2 & 6,45 \\
\hline A TV Câmara é a mais eficiente & 2 & 6,45 \\
\hline TOTAL & $\mathbf{3 1}$ & $\mathbf{1 0 0}$ \\
\hline
\end{tabular}

Fonte: Elaboração própria.

Os dados do questionário revelam disputas pela visibilidade em outro plano, a saber, no âmbito da agenda legislativa. O Quadro 9 mostra que 72,73\% dos respondentes acham que determinados temas recebem mais atenção do que outros na divulgação das audiências públicas.

Quadro 9 - Você acha que existem temas que recebem cobertura mais adequada do que outros?

\begin{tabular}{|l|r|r|}
\hline RESPOSTAS & $\mathbf{N}$ & $\mathbf{\%}$ \\
\hline Sim & 16 & 72,73 \\
\hline Não & 6 & 27,27 \\
\hline TOTAL & $\mathbf{2 2}$ & $\mathbf{1 0 0}$ \\
\hline
\end{tabular}

Fonte: Elaboração própria.

O quadro 10 mostra os temas considerados mais e menos relevantes na divulgação das audiências públicas pelos veículos de comunicação da Câmara. Entre os temas que os informantes acham que são tratados com maior destaque estão os direitos humanos, incluindo os direitos das pessoas com deficiência (19,35\%). A Comissão de Finanças e Tributação aparece com 16,13\%, e os temas ligados a direito, justiça e cidadania registram $12,90 \%$. Defesa do consumidor e seguridade social e família empatam, com $6,45 \%$. Por fim, também empatados, estão assuntos agricultura e pecuária, educação, esportes, desenvolvimento regional e da Amazônia, legislação participativa e segurança pública.

Se há a percepção de alguns dos secretários-executivos das comissões de que a área de direitos humanos é uma das que recebem mais espaço na divulgação, o responsável por este tema disse o contrário: 
Não tenho elementos para avaliar a adequação em todos os temas, mas posso afirmar que o tema da minha comissão - direitos humanos e minorias - recebe menos espaço/atenção do que mereceria, tendo em vista a relevância do tema e o tamanho da população atingida e interessada no mesmo.

Quadro 10 - Temas que recebem cobertura mais adequada

\begin{tabular}{|l|r|r|}
\hline RESPOSTAS & $\mathbf{N}$ & $\mathbf{\%}$ \\
\hline Defesa dos Direitos das Pessoas com Deficiência & 6 & 19,35 \\
\hline Direitos Humanos e Minorias & 6 & 19,35 \\
\hline Finanças e Tributação & 5 & 16,13 \\
\hline Direito, Justiça e Cidadania & 4 & 12,90 \\
\hline Defesa do Consumidor & 2 & 6,45 \\
\hline Seguridade Social e Família & 2 & 6,45 \\
\hline Agricultura, Pecuária, Abastecimento e Desenvolvimento Rural & 1 & 3,23 \\
\hline Educação & 1 & 3,23 \\
\hline Esportes & 1 & 3,23 \\
\hline Integração Nacional, desenvolvimento Regional e da Amazônia & 1 & 3,23 \\
\hline Legislação Participativa & 1 & 3,23 \\
\hline Segurança Pública e Combate ao Crime Organizado & 1 & 3,23 \\
\hline Ciência e Tecnologia, Comunicação e Informática & 0 & 0,00 \\
\hline Desenvolvimento Urbano & 0 & 0,00 \\
\hline Desenvolvimento Econômico, Indústria, Comércio e Serviços & 0 & 0,00 \\
\hline Meio Ambiente e Desenvolvimento Sustentável & 0 & 0,00 \\
\hline Minas e Energia & 0 & 0,00 \\
\hline Relações Exteriores e Defesa Nacional & 0 & 0,00 \\
\hline Trabalho, Administração Pública e Serviço Público & 0 & 0,00 \\
\hline Turismo & 0 & 0,00 \\
\hline Viação e Transportes & 0 & 0,00 \\
\hline TOTAL & $\mathbf{3 1}$ & $\mathbf{1 0 0}$ \\
\hline
\end{tabular}

Fonte: Elaboração própria.

No espaço para comentários, alguns informantes destacaram que "a maior cobertura tem a ver com a importância e a repercussão do tema a ser discutido na audiência pública e não com a área temática das comissões". Outro escreveu o seguinte: 
"Na minha percepção, os veículos de comunicação da Casa estão muito centrados nas atividades do Plenário e do presidente da Casa, deixando de lado a divulgação institucional". Outro informante fez alusão às mudanças na política de divulgação das atividades legislativas em função do estilo de gestão de quem preside a Câmara: “A partir deste ano $^{18}$, nota-se redução de espaço para temas relacionados a direitos humanos, cidadania, movimentos sociais, sociedade civil em geral".

\section{Conclusões}

As conclusões iniciais chamam atenção para a existência de um processo multifatorial de lutas simbólicas, em várias etapas, envolvendo redefinições e negociações constantes entre os gestores da informação da CJor e os representantes das comissões que promovem as audiências públicas, incluindo os próprios parlamentares, os secretários-executivos e corpo funcional dos colegiados e os grupos de interesse envolvidos nos debates. Até o momento foram identificadas cinco seguintes fases de lutas simbólicas.

A primeira - e a mais pacífica - consistiu na ampliação da visibilidade e na adequação dos conteúdos aos padrões jornalísticos, com o início da cobertura (20002002). Na segunda (2003-2005), os conflitos se acentuaram, quando a CJor passou a estabelecer critérios editoriais específicos para pauta e enquadramento, o que desagradou os parlamentares. A terceira ampliou as disputas simbólicas, com a discussão sobre os critérios próprios de cada veículo da Secom (jornal, rádio, TV e internet). A quarta (20062010), resultante da ampliação da visibilidade, incluiu novos atores no campo de lutas simbólicas, como as entidades e os grupos de pressão e de interesse envolvidos na agenda das audiências. A quinta e última fase (2010-2014) amplificou ainda mais esse cenário, com o debate sobre convergência midiática e o início das audiências interativas.

O estudo revela como são acirradas e continuadas as disputas simbólicas em torno do que deve ser divulgado e como deve ocorrer a divulgação. Cada segmento burocrático apresenta discurso que aponta para um horizonte normativo acerca da divulgação das audiências públicas. Do ponto de vista dos gestores de comunicação institucional da Secom, esse horizonte normativo remete para os chamados critérios de noticiabilidade, ou seja, os temas de maior repercussão pública devem receber maior atenção. Para os parlamentares, por sua, vez, o critério de relevância é definido com base no envolvimento

\footnotetext{
${ }^{18}$ Alusão à gestão de Eduardo Cunha na Presidência da Câmara.
} 
direto do parlamentar com a atividade divulgada. Trata-se, como vimos anteriormente, de uma disputa em torno do poder simbólico das palavras e das imagens, com cada segmento tentando interferir para assegurar a sua perspectiva. É o que Miguel (2008) denomina de controle da visibilidade. Por essa razão, a política institucional de divulgação dos veículos de comunicação da Câmara é continuamente questionada pelos parlamentares e seus operadores burocráticos, ou seja, os servidores que atuam na burocracia das comissões. Trata-se de uma disputa entre os valores técnicos (representados pelos discursos dos jornalistas) e os valores políticos (os discursos dos deputados e seus aliados burocráticos), numa clara disputa simbólica, nos termos de Bourdieu.

É interessante notar aqui a configuração de dois tipos de burocracia. Uma é representada pelo corpo de jornalistas e gestores da informação (servidores da Secom) e a outra é como se fosse uma "burocracia híbrida", as equipes que trabalham nas comissões que promovem as audiências públicas. Apesar de todos fazerem parte do mesmo sistema burocrático da Câmara dos Deputados, na prática, é como se fossem dois mundos burocráticos, cada um com uma retórica específica. Quanto mais próximas dos parlamentares, mais as equipes burocráticas aderem aos valores, ideias e opiniões dos deputados, a exemplo do corpo burocrático das comissões, cujo presidente é um parlamentar. No caso da Secom, não há parlamentar na gestão dos veículos de mídia da Casa $^{19}$. Todos os chefes, jornalistas e gestores de informação eram servidores de carreira na época da pesquisa.

Cabe ressaltar ainda as disputas entre as próprias comissões e os parlamentares. A pesquisa chama atenção para a diversidade de comissões, com suas agendas e estratégias de lutas simbólicas que ocorre entre elas. Assim como os parlamentares que presidem as comissões têm sua atuação política marcada pela busca da distinção política, pela individualização de seus feitos e pela conquista e manutenção de sua própria reputação política, as comissões também reproduzem essa forma de atuação. Como vimos na análise, no caso da divulgação dos temas relacionados a direitos humanos, enquanto cerca de $40 \%$ do conjunto dos secretários-executivos das comissões acham que essa é área temática que recebe maior atenção das mídias da Câmara (Quadro 10), na avaliação do secretário-executivo da Comissão de Direitos Humanos e Minorias, as audiências

\footnotetext{
${ }^{19}$ Desde que a Secom foi criada em 1998 era assim que funcionava. A situação mudou em 2015, quando o então presidente da Câmara, Eduardo Cunha, nomeou um deputado para acompanhar a gestão das atividades de comunicação da Secom. Mesmo assim, o que dizem os gestores atuais é que o deputado conhece pouco os veículos e não consegue interferir tanto. Atua principalmente na definição das diretrizes gerais de comunicação, o que explica a manutenção de uma cultura burocrática sem muita proximidade com os deputados.
} 
públicas promovidas pela referida comissão não recebem a devida divulgação.

As controvérsias em torno dessas lutas simbólicas são relevantes como elementos para perspectivar as lógicas de ação de cada segmento envolvido na gestão dos efeitos da visibilidade parlamentar. Além disso, dizem respeito a um aspecto fundamental da política, que é a visibilidade, que, cada vez, mais ocorre pela midiatização da política. Tanto é que estamos tratando de um sistema institucional de midiatização da política.

Acreditamos que os resultados desta pesquisa possam contribuir com o entendimento de que as lutas simbólicas fazem parte do processo político-institucional da Câmara dos Deputados e que os seus efeitos possam ser compreendidos e, quando for o caso, mitigados para tornar o processo político-legislativo o mais adequado possível para contribuir com a resolução de conflitos e anseios da sociedade.

\section{REFERÊNCIAS}

BARROS, Antonio Teixeira de; Bernardes, Cristiane Brum. Dilemas dos sistemas híbridos de comunicação institucional: análise das tensões e dos conflitos no projeto da Câmara dos Deputados. Organicom, v. 12, n. 22, p. 16-37, 2015.

BERNARDES, Cristiane Brum; BARROS, Antonio Teixeira de. A cobertura jornalística das audiências públicas nas mídias legislativas. Estudos em Jornalismo e Mídia, v. 7, p. 260-272, 2010.

BASTOS, Celso Ribeiro; MARTINS, Ives Gandra da Silva. Comentários à Constituição do Brasil. São Paulo: Saraiva, 1995. v. 4.

BOURDIEU, Pierre. O poder simbólico. Rio de Janeiro: Difel, 1989.

BOURDIEU, Pierre. Sobre a televisão. Rio de Janeiro: Zahar, 1997.

BOURDIEU, Pierre.; BOLTANSKI, L. La production de l'idéologie dominante. Paris: Demopolis, 2008.

BOURDIEU, Pierre. L'essence du néolibéralisme. Le Monde Diplomatique, Mars, 1998. Disponível em: http://www.monde-diplomatique.fr/1998/03/BOURDIEU/3609. Acesso em: 28 jun. 2018.

BOURDIEU, Pierre. Espíritos de Estado: gênese e estrutura do campo burocrático. In: BOURDIEU, Pierre. Razões práticas: sobre a teoria da ação. Campinas, São Paulo: Ed. Papirus, 2011a. p. 91-124.

BOURDIEU, Pierre. O campo político. Revista Brasileira de Ciência Política, Brasília, n. 5, p. 193-216, July 2011 b.

CASTRO, Lucia Rabello. Juventude e socialização política: atualizando o debate. Psicologia: Teoria e Pesquisa, v. 25, n. 4, p. 479, 2010. 
CHIARAMONTE, Chiaramonte Rodrigues. Doxa intelectual: conceito e emprego em um caso brasileiro. Primeiros Estudos. São Paulo, n. 3, p. 84-103, 2012.

DAL BOSCO, Maria Goretti. Audiência pública como direito de participação. Revista Jurídica UNIGRAN. Dourados, v. 4, n. 8, p. 137-212, jul./dez. 2002.

GOFFMAN, Erving. Manicômios, prisões e conventos. São Paulo: Perspectiva, 1974.

GUERRA, A. M. V. A Participação Social e as Audiências Públicas. 97 f. Monografia (Especialização em Políticas Públicas) - Centro de Formação, Treinamento e Aperfeiçoamento da Câmara dos Deputados (Cefor), Brasília, 2010.

HABERMAS, Jürgen. Comentários à Ética do Discurso. Lisboa: Instituto Piaget, 1999. $202 \mathrm{p}$.

HABERMAS, Jürgen. O discurso filosófico da modernidade: doze lições. Tradução de Luiz Sérgio Repa e Rodnei Nascimento. São Paulo: Martins Fontes. 2002. 540 p.

HABERMAS, Jürgen. Historia y crítica de la opinión pública. Barcelona: G. Gili, 1994.

HABERMAS, Jürgen. Direito e Democracia: entre facticidade e validade. Rio de Janeiro: Tempo Brasileiro, 1997.

ION, Jacques; RAVON, Bertrand. Causes publiques, affranchissement des appartenances et engagement personnel. Lien Social et Politiques, n. 39, p. 59-71, 1998.

JURIS, Jeffrey S. The new media and activist networking within anticorporate globalization movements. The Annals of the American Academy of Political and Social Science, v. 597, p. 189-208, 2005.

KLÜGER, Elisa. A contraposição das noções de técnica e política nos discursos de uma elite burocrática. Revista de Sociologia e Política, v. 23, n. 55, p. 75-96, 2015.

LIMA, Roberto Kant de. Polícia, justiça e sociedade no Brasil: uma abordagem comparativa dos modelos de administração de conflitos no espaço público. Revista de Sociologia e Política, n. 13, p. 23-38, 1999.

LONG, Norman. Actors, interfaces and development intervention: meaning, purposes and powers. In: KONTINEN, Tiina. (org.). Development intervention: actor and activity perspectives. Helsinki: University of Helsinki. Center for Activity Theory and Developmental Work Research and Institute for Development Studies, 2004, p. 14-36.

MIGUEL, Luis Felipe. Os meios de comunicação e a prática política. Lua Nova, n. 55, p. 155-184, 2002.

MOUFFE, Chantal. On the political. Londres: Routledge, 2005.

RIBEIRO, Renato Janine. O afeto autoritário: televisão, ética e democracia. São Paulo: Ateliê Editorial, 2005. 221 p.

SANT'ANNA, Francisco. Mídia das fontes: um novo ator no cenário jornalístico 
brasileiro. Brasília: Senado Federal, 2009.

TROIANO, Mariele. Atores empresariais, instituições e leis: uma proposta de estudo das audiências públicas nas comissões permanentes. In: ENCONTRO ANUAL DA ASSOCIAÇÃO NACIONAL DOS PROGRAMAS DE PÓS-GRADUAÇÃO EM CIÊNCIAS SOCIAIS (ANPOCS), 39. Anais [...]. Caxambu, 2015.

WEBER, Max. O Parlamento como órgão do Estado e o problema da publicidade da administração. In: WEBER, Max. Economia e Sociedade. Brasília: Editora da UnB, p. 560-580.

Artigo submetido em: 2018-06-13

Reapresentado em: 2018-10-30

Aceito em: 2018-11-28 